\title{
Psychosocial resources and persistent smoking in early pregnancy - a population study of women in their first pregnancy in Sweden
}

Elisabeth Dejin-Karlsson, Bertil S Hanson, Per-Olof Östergren, Jonas Ranstam, Sven-Olof Isacsson, Nils-Otto Sjöberg

\begin{abstract}
Study objective - To test the stress hypothesis by characterising women during their first pregnancy who continue to smoke in early pregnancy in comparison with women who quit smoking, with special reference to psychosocial factors like social network, social support, demands, and control in work and daily life.

Design - The study is based on a cohort of primigravidas followed during pregnancy. Data were collected by self administered questionnaires during the pregnant womens' first antenatal visit at about 12 weeks.
\end{abstract}

Setting - The study was performed in the antenatal clinics in the city of Malmö, Sweden.

Participants - The participants were all primigravidas living in the city of Malmö, Sweden, over a one year period, 1991-92. A total of $872(87.7 \%)$ of the 994 invited women agreed to participate. The population of this study on smoking includes all primigravidas who at the time of conception were smoking $(n=404,46 \cdot 3 \%)$.

Main results - At the first antenatal visit $(63.6 \% \quad(n=257)$ of the prepregnancy smokers were still smoking (a total smoking prevalence of $29.5 \%$ ). The pregnant smokers were on average younger and had a lower educational level. The highest relative risk (RR) of continued smoking was found among unmarried women $R R$ 2.7 (95\% confidence interval) $(1 \cdot 5,4 \cdot 8)$, women having unplanned pregnancies $\mathbf{R R}$ $2 \cdot 2(1 \cdot 2,4 \cdot 0)$ and those with a low social participation $R R 1.6(1 \cdot 0,2 \cdot 7)$, low instrumental support RR $2 \cdot 6(1 \cdot 2,6 \cdot 0)$, low support from the child's father $R R 2 \cdot 1(1 \cdot 0$, $4 \cdot 2)$ and those exposed to job strain $R R=$ $2 \cdot 3(1 \cdot 1,4 \cdot 8)$. The associations were independent of potential confounders such as age, educational level, nationality, cohabiting status, passive smoking, and previous years of smoking.

Conclusions - This study supports the stress hypothesis. Smoking can be one way women handle stress when demands become too great. In order to reduce smoking among pregnant women, maternity centre resources need to be focused more on women with low psychosocial resources who are at highest risk for continued smoking. It is also important to involve actively the woman's partner or other important people in the woman's social network.

(f Epidemiol Community Health 1996;50:33-39)

Smoking is one of the most important risk factors during pregnancy. A dose response association between smoking and low birth weight has been documented ${ }^{1-3}$ and associations have also been noted between maternal smoking and an increased incidence of ectopic pregnancy, ${ }^{4}$ perinatal morbidity, ${ }^{5}$ and late fetal and early neonatal death. ${ }^{6}$ In a Swedish study smoking was found to double the risk of sudden infant death. ${ }^{7}$ There are also reported effects of smoking during pregnancy on the cognitive functioning of children at the age of 3 years. $^{8}$

In recent years great attention has been paid to the dangers of smoking during pregnancy. In spite of this, many pregnant women continue to smoke. In Sweden the prevalence of smoking among all pregnant women was $21.8 \%$ in 1992 (Swedish Medical Birth Registry - personal communication). A study from two big cities in Denmark showed a prevalence of $44 \%$ in 1987 , and $81 \%$ of these women were still smoking at the end of pregnancy. ${ }^{9}$ One Norwegian study in 1989 showed a smoking prevalence of $46 \% 3$ months before pregnancy, and $84 \%$ of the women were still smoking at the time of the first medical check up. ${ }^{10}$ In a Swedish study, $32 \%$ of the pregnant women in one big city were daily smokers at the time of conception and by the time of their antenatal visit, 2 months later, $77 \%$ reported that they were still smoking. ${ }^{11}$

Women's smoking has been seen as related to social deprivation, stress, and disadvantage. ${ }^{12} 13$ Persistent smoking during pregnancy is found to be related to low household incomes, living in rented accommodation, being unmarried, and having a husband or partner in manual employment. ${ }^{14}$ High parity number, not living with the infant's father, and daily passive smoking at home are also associated with an increased risk for continued smoking. ${ }^{15}$ Other important predictors of unsuccessful smoking cessation are a high level of smoking before pregnancy and high coffee consumption. ${ }^{9}$ Women experiencing depression and those with psychosocial difficulties in daily domestic roles also have higher rates of persistent smoking. ${ }^{14}$

Smoking is a complex psychosocial behaviour and can be regarded as a maladaptive 
behaviour, helping the individual to cope with the discomfort generated by the demands and stressful situations in daily life. ${ }^{16-18}$ The smoker's ability to handle demands and stressful situations without cigarettes is conditioned by the presence of different individual and psychosocial resources which can facilitate a healthy coping response. ${ }^{16}{ }^{17}$ It has, for instance, been shown that emotional support given by family and friends has an independent association with smoking cessation and maintenance of cessation ${ }^{19}$ and lack of social support networks is one reason why pregnant women continue to smoke. ${ }^{20}$

Although most pregnant women are aware of the hazards of smoking, many pregnant smokers continue to smoke during pregnancy. ${ }^{21}$ If women quit smoking before the end of the fourth month, the risk to the babies decreases. ${ }^{18}$ Therefore, one of the most important goals for maternity health centres must be to identify women who are at highest risk for continued smoking early, in order to offer them more individualised and specific support to quit smoking.

This study aimed to test the stress hypothesis by characterising women during their first pregnancy who continue to smoke in early pregnancy in comparison with women who quit smoking because they were pregnant with special reference to psychosocial factors such as social network, social support, demands, and control in work and daily life.

\section{Subjects and methods}

STUDY POPULATION

This study is based on a cohort that included all primigravidas living in the city of Malmö (235 000 inhabitants), Sweden, who took part in prenatal care at four antenatal clinics over a one year period. Three of the clinics were public and one was private, and they covered about $85-90 \%$ of all primigravidas living in Malmö. Recruitment occurred between September 1991 and September 1992. A total of 872 $(87 \cdot 7 \%)$ of the 994 invited women agreed to participate. Twenty three per cent $(n=200)$ of the women were not born in Sweden, and about half of these $(n=115)$ had lived in Sweden for only 12 months or less at the time of recruitment. Because of this we used interpreters for $10.8 \%(n=89)$ of the women. The population of this study includes all primigravidas who at the time of conception were smoking $(n=404,46 \cdot 3 \%)$.

During the first antenatal visit (at about 12 weeks) and on the postnatal ward after delivery, all primigravidas were asked to complete a questionnaire. Each woman received a personal letter from the midwife with information about the study and an invitation to participate in it and a questionnaire. This contained items concerning background factors (age, education, nationality, marital, and cohabiting status) and whether the pregnancy was planned; psychosocial factors like social network, social support, and control in daily life; psychosocial characteristics in the workplace; and also lifestyle factors, such as physical activity, alcohol consumption, smoking habits, exposure to passive smoking at home or at work, and the number of years of smoking.

\section{PSYCHOSOCIAL VARIABLES}

A model comprising two main concepts was used. These were social network and social support and they were assessed with a method previously described and validated. ${ }^{22}$ A person's social network is a structural concept and was defined here using two subconcepts:

- Social anchorage - which describes the degree to which the person belongs to and is anchored within formal and informal groups such as relatives, club members, neighbourhood, friends, and the feeling of membership in these groups (four questions).

- Social participation - which describes how actively the person takes part in social activities of formal and informal groups in society (theatre, cinema, church, study circle, sports match and family gatherings) [fourteen questions].

\section{Social support}

Social support is regarded as a function of the person's interactions with her social network and was, in this study, divided into five subconcepts:

- Emotional support - the person's experience of receiving care, encouragement of personal value, and feelings of confidence and trust from relatives, friends, neighbours, and colleagues (three questions).

- Instrumental support - a measure of a person's access to advice, information, material resources and practical service (one question). - Support from the child's father - this refers to the degree of perceived support from the child's father in a general sense and particularly whether he was expected to accompany his partner to childbirth classes (two questions).

- Maternal support - this refers to the degree of support a woman experiences from her own mother (one question).

Based on the items in the questionnaire, six indices were formed (minimum and maximum values are presented). The scores of each index were dichotomised into high/low, as close to the lowest tertile as possible, and the lowest third of the distribution was defined as low.
- Social anchorage
- Social participation
- Emotional support
- Instrumental support
- Support from the child's father
- Maternal support
$0-4$ points
$0-12$ points
$0-3$ points
$0-4$ points
$0-4$ points
$0-5$ points

\section{Control of daily life}

This pertains to the woman's experiences of being able to control important aspects of her daily life, including how she deals with personal problems, according to a method described and validated by Cohen and Williamson ${ }^{23}$ (four questions). 
Table 1 Differences between participants and nonparticipants according to age, marital status and nationality

\begin{tabular}{|c|c|c|c|c|c|}
\hline & \multicolumn{2}{|c|}{ Participant } & \multicolumn{2}{|c|}{ Non-participant } & \multirow[t]{2}{*}{$p$ value } \\
\hline & No & $(\%)$ & No & $(\%)$ & \\
\hline $\begin{array}{l}\text { Maternal age (y) } \\
15-24 \\
25-29 \\
30-44\end{array}$ & $\begin{array}{l}259 \\
364 \\
249\end{array}$ & $\begin{array}{l}(29 \cdot 7) \\
(41 \cdot 7) \\
(28 \cdot 6)\end{array}$ & $\begin{array}{l}56 \\
33 \\
33\end{array}$ & $\begin{array}{l}(45 \cdot 9) \\
(27 \cdot 0) \\
(27 \cdot 0)\end{array}$ & $<0.001$ \\
\hline $\begin{array}{l}\text { Marital status } \\
\text { Married } \\
\text { Unmarried } \\
\text { (Missing) }\end{array}$ & $\begin{array}{l}325 \\
535 \\
(12)\end{array}$ & $\begin{array}{l}(37 \cdot 8) \\
(62 \cdot 2)\end{array}$ & $\begin{array}{l}45 \\
64 \\
(13)\end{array}$ & $\begin{array}{l}(41 \cdot 3) \\
(58 \cdot 7)\end{array}$ & $0 \cdot 48$ \\
\hline $\begin{array}{l}\text { Nationality } \\
\text { Swedish } \\
\text { Non-Swedish } \\
\text { (Missing) } \\
\text { Total }\end{array}$ & $\begin{array}{l}668 \\
200 \\
(4) \\
872\end{array}$ & $\begin{array}{l}(77 \cdot 0) \\
(23 \cdot 0) \\
(100)\end{array}$ & $\begin{array}{l}51 \\
59 \\
(12) \\
122\end{array}$ & $\begin{array}{l}(46 \cdot 4) \\
(53 \cdot 6) \\
(100)\end{array}$ & $<0.001$ \\
\hline
\end{tabular}

\section{fob demands and job control}

These two psychosocial aspects of the workplace, are measured using a two dimensional model developed and validated by Karasek and Theorell. ${ }^{24}$ The job demands dimension covers the extent of psychological demands such as hectic work, work overload, role ambiguity etc (five questions). The job control dimension covers the degree of decision latitude experienced over and in the work situation and opportunities to learn new things (six questions). An active job is signified by a combination of a high level of demands and high job control, a passive job by low demands and low job control, job strain is the combination of high demands and low job control and a relaxed job is characterised by low demands and high degree of job control. Fob support describes the workplace atmosphere and conditions including the understanding and support received from supervisors and workmates (six questions).

\section{LIFESTYLE VARIABLES}

Three smoking categories were defined: prepregnancy smokers are women who were smoking at the time of conception; prenatal smokers are women who at the first antenatal visit reported that they smoked regularly or irregularly; prenatal quitters are defined as those women who at their first antenatal visit reported that they had quit smoking because of pregnancy.

To validate data on smoking from the questionnaire a comparison was made with data on smoking from the medical records. The information in the medical records is collected by the midwife at the same point in time (the first visit to the antenatal clinic) and the women's smoking habits are recorded as either non-smoker, smoking $<10$ cigarettes $/ \mathrm{d}$, or smoking $\geq 10$ cigarettes/d.

An adjusted, quantity-frequency method was used to estimate the women's consumption of alcohol. ${ }^{25}$ They were asked about their alcohol habits during the last year and their consumption of beer, wine and spirits during the last 30 days. Three categories were defined: abstainers who had not drunk anything in the last year, consumers who were still drinking and those women who had stopped drinking because of pregnancy.
Table 2 Background and lifestyle characteristics of the 404 women who smoked before pregnancy

\begin{tabular}{|c|c|c|}
\hline Characteristics & No & (\%) \\
\hline $\begin{array}{l}\text { Maternal age (y) } \\
15-24 \\
25-29 \\
30-44\end{array}$ & $\begin{array}{l}139 \\
164 \\
101\end{array}$ & $\begin{array}{l}(34.5) \\
(40 \cdot 7) \\
(24.8)\end{array}$ \\
\hline $\begin{array}{l}\text { Educational level (y) } \\
\quad \leq 9 \\
10-12 \\
>12 \\
\text { (Missing) }\end{array}$ & $\begin{array}{l}113 \\
169 \\
117 \\
(5)\end{array}$ & $\begin{array}{l}(28 \cdot 3) \\
(42 \cdot 4) \\
(29 \cdot 3)\end{array}$ \\
\hline $\begin{array}{l}\text { Nationality } \\
\text { Swedish } \\
\text { Non-Swedish } \\
\text { (Missing) }\end{array}$ & $\begin{array}{c}335 \\
68 \\
(1)\end{array}$ & $\begin{array}{l}(83 \cdot 1) \\
(16 \cdot 9)\end{array}$ \\
\hline $\begin{array}{l}\text { Marital status } \\
\text { Married } \\
\text { Unmarried } \\
\text { (Missing) }\end{array}$ & $\begin{array}{r}89 \\
309 \\
(6)\end{array}$ & $\begin{array}{l}(22 \cdot 4) \\
(77 \cdot 6)\end{array}$ \\
\hline $\begin{array}{l}\text { Cohabitng status } \\
\text { (with the child's father) } \\
\text { Cohabiting } \\
\text { Not cohabiting } \\
\text { (Missing) }\end{array}$ & $\begin{array}{c}332 \\
68 \\
(4)\end{array}$ & $\begin{array}{l}(83 \cdot 0) \\
(17 \cdot 0)\end{array}$ \\
\hline $\begin{array}{l}\text { Planned pregnancy } \\
\text { Yes } \\
\text { No } \\
\text { (Missing) }\end{array}$ & $\begin{array}{l}262 \\
136 \\
(6)\end{array}$ & $\begin{array}{l}(65 \cdot 8) \\
(34 \cdot 2)\end{array}$ \\
\hline $\begin{array}{l}\text { Physical activities } \\
\text { Low } \\
\text { Moderate } \\
\text { High } \\
\text { (Missing) }\end{array}$ & $\begin{array}{r}100 \\
227 \\
76 \\
(1)\end{array}$ & $\begin{array}{l}(24 \cdot 8) \\
(56 \cdot 3) \\
(18 \cdot 9)\end{array}$ \\
\hline $\begin{array}{l}\text { Alcohol consumption } \\
\text { Abstainer } \\
\text { Stopped due to pregnancy } \\
\text { Consumer } \\
\text { (Missing) }\end{array}$ & $\begin{array}{r}42 \\
169 \\
182 \\
(11)\end{array}$ & $\begin{array}{l}(10 \cdot 7) \\
(43 \cdot 0) \\
(46 \cdot 3)\end{array}$ \\
\hline $\begin{array}{l}\text { Years of smoking } \\
\quad 1-5 \\
6-9 \\
\geq 10 \\
\text { (Missing) }\end{array}$ & $\begin{array}{l}122 \\
103 \\
159 \\
(20)\end{array}$ & $\begin{array}{l}(31 \cdot 8) \\
(26 \cdot 8) \\
(41 \cdot 4)\end{array}$ \\
\hline $\begin{array}{l}\text { Exposed to passive smoking } \\
\text { Yes } \\
\text { No } \\
\text { (Missing) } \\
\text { Total }\end{array}$ & $\begin{array}{l}326 \\
73 \\
(5) \\
404\end{array}$ & $\begin{array}{l}(81 \cdot 7) \\
(18 \cdot 3) \\
(100 \cdot 0)\end{array}$ \\
\hline
\end{tabular}

Physical activity was assessed by one question and high physical activity was defined as heavy exercise or athletics such as running, swimming, playing tennis and badminton, gymnastics, or heavy gardening for at least 2 hours a week. Moderate physical activity was defined as walking, cycling, light gardening etc for at least 4 hours a week and low physical activity was defined as mostly sedentary such as reading and watching $\mathrm{TV}^{26}$

\section{STATISTICAL METHOD}

$\chi^{2}$ analysis was used to investigate the differences between participants and non-participants. As a measure of the amount of agreement between data on smoking from our questionnaire and from the medical records we used the kappa ( $\kappa$ ) statistic. The calculation of relative risks (RR) and $95 \%$ confidence intervals (95\% CI) was used to analyse the associations between smoking habits and the different background and psychosocial factors. Multiple logistic regression analysis was performed in order to adjust the estimated relative risks for the influence of potential confounders (maternal age, educational level, nationality, cohabiting status, passive smoking, and previous years of smoking). A difference was considered statistically significant if $p<0 \cdot 05$. The 
Table 3 Differences between data on smoking from questionnaire and from medical records $(n=748)$

\begin{tabular}{|c|c|c|c|c|c|}
\hline \multirow[t]{3}{*}{ Medical records } & \multicolumn{5}{|c|}{ Questionnaire } \\
\hline & \multicolumn{2}{|c|}{ Smokers } & \multicolumn{2}{|c|}{ Non-smokers } & \multirow{2}{*}{$\begin{array}{l}\text { Total } \\
\text { No }\end{array}$} \\
\hline & No & $(\%)$ & No & $(\%)$ & \\
\hline $\begin{array}{l}\text { Smokers } \\
\text { Non-smokers } \\
\text { Total }\end{array}$ & $\begin{array}{r}195 \\
17 \\
212\end{array}$ & $\begin{array}{r}(92 \cdot 0) \\
(8 \cdot 0) \\
(100 \cdot 0)\end{array}$ & $\begin{array}{r}9 \\
527 \\
536\end{array}$ & $\begin{array}{r}(1 \cdot 7) \\
(98 \cdot 3) \\
(100 \cdot 0)\end{array}$ & $\begin{array}{l}204 \\
544 \\
748\end{array}$ \\
\hline
\end{tabular}

statistical analysis was made using the SPSS programme. $^{27}$

The study was approved by the Ethics Committee of Lund University and by the Swedish Data Inspection Board.

\section{Results}

Altogether $87 \cdot 7 \%(n=872)$ of the women chose to participate in the cohort. The non-

Table 4 Associations between background and lifestyle characteristics and persistent smoking in early pregnancy presented as crude relative risks (RR), adjusted $R R$ and $95 \%$ confidence intervals (95\% CI)

\begin{tabular}{|c|c|c|c|}
\hline \multirow{3}{*}{$\begin{array}{l}\text { Background and lifestyle } \\
\text { characteristics }\end{array}$} & \multirow[t]{3}{*}{ No } & \multicolumn{2}{|c|}{ Persistent smoking in early pregnancy } \\
\hline & & \multicolumn{2}{|l|}{$R R(95 \% C I)$} \\
\hline & & Crude $R R$ & Adjusted $R R^{*}$ \\
\hline $\begin{array}{l}\text { Maternal age }(y) \\
15-24 \\
25-29 \\
30-44\end{array}$ & $\begin{array}{l}96 \\
99 \\
62\end{array}$ & $\begin{array}{l}1.0 \\
0.7(0.4,1 \cdot 1) \\
0.7(0.4,1.2)\end{array}$ & $\begin{array}{l}1.0 \\
0.5(0.3,1.0) \\
0.4(0.2,1.0)\end{array}$ \\
\hline $\begin{array}{l}\text { Educational level }(y) \\
\quad \leq 9 \\
\quad 10-12 \\
>12\end{array}$ & $\begin{array}{r}90 \\
101 \\
62\end{array}$ & $\begin{array}{l}1 \cdot 0 \\
0.4(0.2,0 \cdot 7) \\
0.3(0.2,0.5)\end{array}$ & $\begin{array}{l}1.0 \\
0.5(0.3,0.9) \\
0.4(0.2,0.9)\end{array}$ \\
\hline $\begin{array}{l}\text { Nationality } \\
\quad \text { Swedish } v \text { non-Swedish }\end{array}$ & $222 / 34$ & $2 \cdot 0(1 \cdot 2,3 \cdot 3)$ & $1 \cdot 7(1 \cdot 0,3 \cdot 1)$ \\
\hline $\begin{array}{l}\text { Marital status } \\
\text { Unmarried } v \text { married }\end{array}$ & $213 / 40$ & $2 \cdot 7(1 \cdot 7,4 \cdot 4)$ & $2 \cdot 7(1 \cdot 5,4 \cdot 8)$ \\
\hline $\begin{array}{l}\text { Cohabiting status } \\
\text { Not cohabiting } v \text { cohabiting }\end{array}$ & $54 / 199$ & $2 \cdot 6(1 \cdot 4,4 \cdot 8)$ & $1 \cdot 9(0 \cdot 9,3 \cdot 7)$ \\
\hline $\begin{array}{l}\text { Planned pregnancy } \\
\text { No } v \text { yes }\end{array}$ & $106 / 146$ & $2 \cdot 8(1 \cdot 7,4 \cdot 5)$ & $2 \cdot 2(1 \cdot 2,4 \cdot 0)$ \\
\hline $\begin{array}{l}\text { Exposed to passive smoking } \\
\text { Yes } v \text { no }\end{array}$ & $221 / 32$ & $2 \cdot 7(1 \cdot 6,4 \cdot 5)$ & $2 \cdot 1(1 \cdot 2,3 \cdot 8)$ \\
\hline $\begin{array}{l}\text { Years of smoking } \\
1-5 \\
6-9 \\
\geq 10\end{array}$ & $\begin{array}{r}68 \\
70 \\
115\end{array}$ & $\begin{array}{l}1 \cdot 0 \\
1 \cdot 7(1 \cdot 0,2 \cdot 9) \\
2 \cdot 1(1 \cdot 3,3 \cdot 4)\end{array}$ & $\begin{array}{l}1.0 \\
1.9(1 \cdot 0,3 \cdot 6) \\
3 \cdot 7(1.9,7 \cdot 1)\end{array}$ \\
\hline $\begin{array}{l}\text { Physical activity } \\
\text { Low } \\
\text { Moderate } \\
\text { High }\end{array}$ & $\begin{array}{r}74 \\
139 \\
43\end{array}$ & $\begin{array}{l}1.0 \\
0.6(0.3,0.9) \\
0.5(0.2,0.9)\end{array}$ & $\begin{array}{l}1.0 \\
0.5(0.3,1.0) \\
0.5(0.2,1.0)\end{array}$ \\
\hline $\begin{array}{l}\text { Alcohol consumption } \\
\text { Abstainer } \\
\text { Stopped because of pregnancy } \\
\text { Consumer }\end{array}$ & $\begin{array}{r}27 \\
99 \\
123\end{array}$ & $\begin{array}{l}1 \cdot 0 \\
0 \cdot 8(0 \cdot 4,1 \cdot 6) \\
1 \cdot 2(0 \cdot 6,2 \cdot 3)\end{array}$ & $\begin{array}{l}1 \cdot 0 \\
0 \cdot 9(0 \cdot 4,2 \cdot 0) \\
1 \cdot 4(0 \cdot 6,3 \cdot 3)\end{array}$ \\
\hline
\end{tabular}

* Adjustment made for maternal age, educational level, nationality, cohabiting status, passive smoking and years of smoking.

Table 5 Associations between psychosocial characteristics and persistent smoking in early pregnancy presented as crude relative risks (RR), adjusted $R R$ and $95 \%$ confidence intervals $(95 \% \mathrm{CI})$

\begin{tabular}{|c|c|c|c|}
\hline \multirow{3}{*}{$\begin{array}{l}\text { Psychosocial characteristics } \\
\text { Low } \mathrm{v} \text { high }\end{array}$} & \multirow[t]{3}{*}{ No } & \multicolumn{2}{|c|}{ Persistent smoking in early pregnancy } \\
\hline & & \multicolumn{2}{|l|}{$R R(95 \% C I)$} \\
\hline & & Crude $R R$ & Adjusted $R R^{*}$ \\
\hline Social anchorage & $70 / 170$ & $1.2(0.8,1.9)$ & $1 \cdot 2(0 \cdot 7,2 \cdot 0)$ \\
\hline Social participation & $127 / 124$ & $2.2(1.5,3.4)$ & $1 \cdot 6(1 \cdot 0,2 \cdot 7)$ \\
\hline Instrumental support & $36 / 220$ & $2 \cdot 0(1 \cdot 0,4 \cdot 1)$ & $2 \cdot 6(1 \cdot 2,6 \cdot 0)$ \\
\hline Emotional support & $83 / 171$ & $1 \cdot 3(0 \cdot 8,2 \cdot 1)$ & $1 \cdot 3(0 \cdot 8,2 \cdot 2)$ \\
\hline Support from the child's father & $65 / 156$ & $3 \cdot 2(1 \cdot 7,5 \cdot 9)$ & $2 \cdot 1(1 \cdot 0,4 \cdot 2)$ \\
\hline Maternal support & $81 / 172$ & $1 \cdot 3(0 \cdot 9,2 \cdot 1)$ & $1 \cdot 3(0 \cdot 8,2 \cdot 2)$ \\
\hline Job support & $130 / 102$ & $1.0(0.7,1.6)$ & $0.8(0.5,1.4)$ \\
\hline Control of daily life & $83 / 166$ & $1 \cdot 1(0.7,1 \cdot 7)$ & $1 \cdot 1(0 \cdot 7,1 \cdot 8)$ \\
\hline
\end{tabular}

* Adjustment made for maternal age, educational level, nationality, cohabiting status, passive smoking and years of smoking. participant group differed from the participant group in that more women were in the 15-24 age group and were not born in Sweden (Table 1). The groups did not differ with respect to outcome variables such as infant birth weight and gestational age. The mean (SD) birth weights in the participant and non-participant groups were $3366 \mathrm{~g}$ (594) and $3338 \mathrm{~g}$ (663) respectively. The mean (SD) gestational age were $39 \cdot 3$ weeks $(2 \cdot 0)$ and $39 \cdot 2$ weeks $(2 \cdot 6)$ respectively.

Forty six per cent $(n=404)$ were prepregnancy smokers. Background characteristics of the 404 prepregnancy smokers are presented in table 2. Most of the smoking primigravidas were not married but they were, to a high degree, cohabiting with the child's father. Seventeen per cent of the women were not born in Sweden. Nearly half $(46.3 \%)$ continued to drink beer, wine, or spirits during pregnancy and $41.4 \%$ had smoked for 10 years or more.

At their first antenatal visit $63.6 \%(n=257)$ of the prepregnancy smokers reported that they were still smoking - that is, $29.5 \%$ of all women smoked in early pregnancy. The prevalence of smoking in the Medical Birth Registry, Swedish National Board of Health and Welfare for primigravidas in Malmö in 1992 was $26.3 \%$ (Swedish Medical Birth Registry, personal communication). According to the medical records $27 \cdot 2 \%(n=205)$ of women in our total study population were smokers, $18.3 \%$ smoked $<10$ cigarettes/d and $8.9 \%$ smoked $\geq 10$ cigarettes/d. Information about smoking in the medical records was missing for $13.3 \%(n=$ 116) of the women. When comparing information collected from questionnaries with those from the medical records, a high degree of accordance was noted (kappa $=0.91$ ) (Table 3 ). In order to investigate the possible existence of a differential misclassification the analysis was also made stratified for the two categories of the different psychosocial variables (high and low). No indication of a differential misclassification was found.

Women with the shortest duration of education more often continued to smoke, and so did women born in Sweden, unmarried women, women not cohabiting with the child's father, and those having an unplanned pregnancy. Women with low physical activity also continued to smoke to a higher degree and so did primigravidas who were exposed to passive smoking at home or in the workplace and women who had smoked for a longer time. In the multivariate analysis, adjustments were made for the potential confounders such as age, educational level, nationality, cohabiting status, passive smoking, and years of smoking. The relative risks decreased somewhat, though all, with the exception of not cohabiting, were still statistically significant (Table 4 ).

Low social participation showed a statistically significant association with persistent smoking $(R R=2 \cdot 2)$ in the univariate analysis. Low instrumental support and low support from the child's father also showed significant associations with persistent smoking ( $R R=2 \cdot 0$ and $R R=3 \cdot 2$, respectively). In the multivariate 
Table 6 Associations between psychosocial work characteristics and persistent smoking in early pregnancy presented as crude relative risks (RR), adjusted $R R$ and $95 \%$ confidence intervals $(95 \% \mathrm{CI})$

\begin{tabular}{llll}
\hline Psychosocial work characteristics & No & \multicolumn{2}{l}{ Persistent smoking in early pregnancy } \\
\cline { 3 - 4 } & & \multicolumn{2}{l}{$R R(95 \% C I)$} \\
\cline { 3 - 4 } & & Crude $R R$ & Adjusted $R R^{*}$ \\
\hline Relaxed job & 49 & $1 \cdot 0$ & $1 \cdot 0$ \\
Active job & 38 & $0 \cdot 8(0 \cdot 4,1 \cdot 4)$ & $0 \cdot 7(0 \cdot 4,1 \cdot 5)$ \\
Job strain & 74 & $2 \cdot 5(1 \cdot 3,4 \cdot 8)$ & $2 \cdot 3(1 \cdot 1,4 \cdot 8)$ \\
Passive job & 51 & $1 \cdot 1(0 \cdot 6,2 \cdot 1)$ & $1 \cdot 3(0 \cdot 7,2 \cdot 8)$ \\
\hline
\end{tabular}

* Adjustment made for maternal age, nationality, cohabiting status, passive smoking and years of smoking. those attending two private clinics. There is good reason to believe that almost all women with non-Swedish backgrounds were approached, since women who see private obstetricians are usually of Swedish nationality. The participation rate in the study was high $(87 \cdot 7 \%)$. Analysis of the non-participant group showed some minor differences regarding age and nationality but not regarding pregnancy outcomes such as birth weight and gestational age. Our findings showed that it was the younger women who more often continued to smoke during pregnancy. As the non-participants comprised a greater proportion of younger women this could mean that the nonparticipants comprised more smokers than the participants. Besides, if there were a selection bias this would promote an underestimation of the relationship between low psychosocial resources and persistent smoking, but the high participation rate should minimise the problem of a selection bias.

All psychosocial variables in this study are developed and defined from a theoretical perspective of social resources. The concepts are carefully differentiated and included in a theoretical model in order to specify the relations between the various concepts. Both structural and functional aspects of social network and social support are included. Therefore, the constructive validity of various concepts is high and the instrument has in various studies been able to show associations with cardiovascular risk factors, lifestyle factors and to predict mortality. ${ }^{19223536}$ The reliability (test-retest stability) of the instrument has also been found to be sufficient ${ }^{1935}$ as has the internal consistency. ${ }^{1935}$ Besides, we have no reason to believe that there is a higher degree of differential misclassification of the psychosocial variables between the two categories of smoking.

Prenatal smokers in this study were defined as women who smoked either regularly or irregularly. However, irregular smokers did not differ from regular smokers with regard to background, lifestyle, and psychosocial characteristics except for fewer previous years of smoking. The smoking variable was validated by comparing data from medical records with data from questionnaires. A high degree of accordance was found and we did not find any evidence of a differential misclassification between the different categories of psychosocial exposure. The prevalence of smoking in our study was $29.5 \%$, only somewhat higher than that in the medical records with data collected by the midwives $(27 \cdot 2 \%)$. Possible explanations may be that the midwives recorded irregular smokers as non-smokers or that pregnant women are more accurate when answering a questionnaire compared with being interviewed by their midwives. ${ }^{37} \mathrm{~A}$ comparison of self reported smoking with biochemical measures (cotinine, thiocyanate, and carbon monoxide) show that self reports of smoking are accurate in most studies. ${ }^{38}$

The smoking prevalence at the time of conception in our study of primigravidas was high at $46 \cdot 3 \%$. Comparable studies in the Nordic countries, where the study populations include 
both primigravidas and multigravidas, show a smoking prevalence of $44 \%$ for Denmark, ${ }^{9} 46 \%$ for Norway, ${ }^{11}$ and $32 \%$ for Sweden. ${ }^{15}$ The higher Swedish prevalence in our study is probably explained by the fact that we classified smokers as those women who smoked regularly or irregularly while other studies characterised women as smokers only if they smoked daily.

In this study we found a lower rate of persistent smoking during pregnancy $(63.6 \%)$, compared with other studies from Denmark $(81 \%),{ }^{9}$ Norway $(84 \%),{ }^{10}$ and Sweden $(77 \%) .{ }^{11}$ There could be various explanations for these differences. One reason is that our classification of smokers included both regular and irregular smokers and it is easier for irregular smokers to stop smoking. Finally, the other three studies included all pregnancies and primigravidas are known to have a greater propensity to quit smoking than multigravidas. ${ }^{91015}$

Age, educational level, nationality, cohabiting status, passive smoking, and number of previous years of smoking could be confounders of the associations between the psychosocial variables and persistent smoking. Adjusting for these confounders, however, only marginally affected the relative risk related to persistent smoking.

Research on smoking and stopping smoking is an applied study discipline using knowledge from biological, clinical, and public health sciences. ${ }^{39}$ The process of obtaining and giving up smoking is complex, and involves social, psychological and physiological factors. ${ }^{160}$ Health related behaviours like smoking are a result of the interaction between a person and her environment. A person's relation to her environment can be viewed as a dynamic process, because of environmental changes requiring continuous adaptation by the individual. For successful adaptation, a person needs different resources, for example individual ones such as personal characteristics, education, and financial resources and also material and social resources, that is, social relations. The availability of psychosocial resources such as social network and social support is of potential importance in enabling someone to cope with different stressful situations in daily life. Being pregnant, especially for the first time, is a new and stressful situation in life, and a woman needs different types of resources to cope with and adapt to this new situation. When there is a discrepancy between the woman's perceptions of the demands made on her and her ability to cope with these demands, she could be less likely to succeed in stopping smoking. Smoking can thus be seen as a maladapive reaction helping the smoker to cope with the discomfort generated by the stressful situation of being pregnant for the first time.

The degree of nicotine dependency may also play a role. ${ }^{41}$ In our study the risk of persistent smoking increased with the number of previous years of smoking. Although there is a greater likelihood that heavy smokers continue to smoke compared with light smokers, ${ }^{32}$ there are light smokers who cannot stop, just as there are heavy smokers who quit easily. ${ }^{16}$ Also, the smoking habits of people around her may be of importance to the woman's risk of continuing to smoke..$^{9153233}$ In the present study, women were less likely to give up smoking if they were exposed to passive smoking at home or at work.

\section{CONCLUSIONS}

The main findings of this study are the associations found between different social and psychosocial factors and persistent smoking during early pregnancy. Unmarried women and women with unplanned pregnancies more often continued to smoke and so did women with low social participation, low instrumental support, low support from the child's father, and women exposed to job strain.

Our study gives support to the stress model - that is, the fact that lack of psychosocial resources means reduced ability to deal with the new demands associated with pregnancy. Smoking can then be regarded as one way women can handle stress. As the present study is cross sectional we are, however, unable to comment on the direction of the associations regarding some of the psychosocial factors and continued smoking during pregnancy. A prospective study is needed before reaching such definite conclusions.

The finding that psychosocial factors could influence persistent smoking during pregnancy should have important implications for programme planning and in the development of maternity care. The existing scientific basis for antenatal care routines is unsatisfactory in some ways. ${ }^{21}$ In the Nordic countries compliance with the routine programme is extremely high. Sweden, for instance, has a very high mean number of routine antenatal visits, 13 per pregnancy, even for very healthy women. ${ }^{22}$ Since smoking is one of the most important risk factors during pregnancy, women should be classified as high risk or low risk according to their smoking habits as soon as their first antenatal visit. By identifying the women who are at the highest risk for continued smoking, that is younger women, women with unplanned pregnancies, women with low education, and those with low psychosocial resources, the midwives should offer them additional visits and more individualised and specific intervention programmes. It is also important that intervention programmes targeted at this group should actively involve the woman's partner or other important persons in her social network.

This study has been made possible by a grant from The Swedish Council for Social Research, The Swedish Council for Planning and Coordination of Research, The Medical Faculty at Lund University and The University Hospital, MAS, in Malmö.

1 Brooke O, Anderson R, Bland M, Peacock J, Stewart M. Effects on birth weight of smoking, alcohol, caffeine, socioeconomic factors, and psychosocial stress. $B M \mathcal{F}$ 1989;298:795-801

2 Ericson A, Gunnarskog J, Källen B, Otterblad-Olausson P. Surveillance of smoking during pregnancy in Sweden, 1983-1987. Acta Obstet Gynecol Scand 1991;70:111-17.

3 Backe B. Maternal smoking and age. Acta Obstet Gynecol Scand 1993;72:172-6.

4 Coste J, Job-Spira N, Fernandez H. Increased risk of ectopic pregnancy with maternal cigarette smoking. Am $₹$ Public Health 1991;81:199-200.

5 Ahlsten G, Cnattingius S, Lindmark G. Cessation of smoking during pregnancy improves foetal growth and reduces 
infant morbidity in the neonatal period. A populationbased prospective study. Acta Paediatr 1993;82:177-81.

6 Cnattingius S, Haglund B, Meirik O. Cigarette smoking as risk factor for late fetal and early neonatal death. $B M^{f}$ 1988;297:258-61.

7 Haglund B, Cnattingius S. Cigarette smoking as a risk factor for sudden infant death syndrome: A population-based study. Am F Public Health 1990;80:29-32.

8 Sexton M, Fox N, Hebel R. Prenatal exposure to tobacco: II Effects on cognitive functioning at age three. Int $f$ Epidemiol 1990;19:72-7.

9 Olsen J. Predictors of smoking cessation in pregnancy. Scand f Soc Med 1993;3:197-202

10 Haug K. Aarö LE, Fugelli P. Smoking habits in early pregnancy and attitudes towards smoking cessation among pregnant

11 Cnattingius $S$, Thorslund $M$. Smoking behaviour among pregnant women prior to antenatal care registration. Soc Sci Med 1990;31:1271-5.

12 Oakley $A$. Who cares for health? Social relations, gender, and the public health. $\mathcal{F}$ Epidemiol Community Health 1994, 48:427-34.

13 Graham H. Women's smoking and family health. $S o c S c i$ Med 1987;25:47-56.

14 Pritchard CW. Depression and smoking in pregnancy in Scotland. $\mathcal{F}$ Epidemiol Community Health 1994;48:377-82.

15 Cnattingius S, Lindmark G, Meirik O. Who continues to Cnattingius S, Lindmark G, Meirik O. Who continues to
smoke while pregnant? $f$ Epidemiol Community Health smoke while preg
1992;46:218-21.

16 Ockene JK, Nuttall R, Benfari RC, Hurwitz I, Ockene IS. A psychosocial model of smoking cessation and maintenance of cessation. Prev Med 1981;10:623-38.

17 Ockene JK, Benfari RC, Nuttall RL, Hurwitz I, Ockene IS Relationship of psychosocial factors to smoking behavior change in an intervention program. Prev Med 1982;11: 13-28.

18 Rutter DR, Quine L. Inequalities in pregnancy outcome: a review of psychosocial and behavioural mediators. Soc $S_{c i}$ review of psychosocial

19 Hanson BS, Isacsson SO, Janzon L. Social support and quitting smoking for good. Is there an association? Results from the population study, "Men born in 1914", Malmö, Sweden. Addict Behav 1990;15:221-33.

20 Maclaine K, Macleod Clark J. Women's reasons for smoking in pregnancy. Nursing Times 1991;87:39-42.

21 Lindmark $G$, Cnattingius $S$. The scientific basis of antenatal care. Report from a state-of-the-art conference. Acta Obstet Gynecol Scand 1991;70:105-9.

22 Hanson BS, Östergren P-O. Different social network and social support characteristics, nervous problems and insomnia: Theoretical and methodological aspects on some results from the population study "Men born in 1914", Malmö, Sweden. Soc Sci Med 1987;25:849-59.

23 Cohen S, Williamsson GM. Perceived stress in a probability sample of the United States. In: Spacapan S, Oskamp $\mathrm{S}$, eds. The social psychology of health. The Claremont symposium on applied social psychology. Newbury Park: Sage Publications, 1988.

24 Karasek R, Theorell T. Healthy work. Stress productivity, and the reconstruction of working life. New York: Basic Books, 1990.

25 Armor DJ, Polich JM. Measurement of alcohol consumption. In: Pattison EM, Kaufman E, eds. Encyclopedic handbook of alcoholism. New York: Gardner Press, 1982 125-6.

26 Grimby G, Wilhelmsen L, Björnstorp P, Saltin B, Tibblin G. Habitual physical activity. Aerobic power and blood lipids. In: Pernow B, Saltin B eds. Muscle metabolism during exercise. New York: Plenum Press, 1971:469-81.

27 Norusis MJ. The SPSS guide to data analysis for release 4. Chicago; SPSS Inc, 1990.

28 Coppotelli $\mathrm{CH}$, Orleans TC. Partner support and other determinants of smoking cessation maintenance among women. $f$ Consult Clin Psychol 1985;53:455-60.

29 Cohen S, Lichtenstein E. Partner behaviors that support quitting smoking. $₹$ Consult Clin Psychol 1990;58:304-9.

30 Gjerdingen DK, Froberg DG, Fontaine P. The effects of social support on women's health during pregnancy, labo and delivery and the postpartum period. Fam Med 1991, 23:370-5.

31 Fingerhut L, Kleinman J, Kendrick J. Smoking before, during and after pregnancy. Am $\mathcal{F}$ Public Health 1990;80 $541-4$.

32 Ockene JK. Smoking among women across the life span: Prevalence, interventions, and implications for cessation research. Ann Behav Med 1993;15:135-48.

33 Quinn V, Dolan Mullen P, Ershoff D. Women who stop smoking spontaneously prior to prenatal care and predictors of relapse before delivery. Addict Behav 1991;16: dictors

34 Homer CJ, James SA, Siegel E. Work-related psychosocial stress and risk of preterm, low birthweight delivery. $A m \mathcal{J}$ Public Health

35 Hanson BS. Social network, social support and health in elderly men. A population study. Malmö University of Lund, 1988 MD Thesis.

36 Hanson BS. Social network, social support and heavy drinking in elderly men - a population study of men born in 1914, Malmö, Sweden. Addiction 1994;89:725-32.

37 Ihlen BM, Amundsen A, Trönnes L, Sande HA. Changes in alcohol and tobacco use during pregnancy. Nordis Alkoholtidskrift 1994;11:91-9.

38 Patrick DL, Cheadle A, Thompson DC, Diehr P, Koepsell T, Kinne S. The validity of self-reported smoking: A review and meta-analysis. Am f Public Health 1994;84: review and

39 Abrams DB. Treatment issues: toward a stepped-care model. Tobacco Control 1993;2(suppl):S17-29.

40 Haire-Joshu D, Morgan G, Fischer EB. Determinants of cigarette smoking. Clin Chest Med 1991;12:711-25.

41 Schachter S, Silverstein B, Kozlowski LT, Perlick D Herman CP, Liebling B. Studies of the interaction of psychological and pharmacological determinants of smoking. $\mathcal{F}$ Exp Psychol (Gen) 1977;106:3-40. 